REFLEXIÓN

Recibido: $16 / 10 / 2013$

Revisado: $16 / 11 / 2013$

Aprobado: 16/12/2013

\title{
EL INTERCAMBIO SIMBÓLICO Y LAS ANTINOMIAS DE LA ECONOMÍA DE MERCADO
}

\author{
Miniensayo sobre: Otras economías
}

\author{
AUGUSTO VELÁSQUEZ FORERO
}

Universidad del Cauca

\section{RESUMEN}

La posibilidad de otras economías diferentes a las estructuras microeconómicas impartidas por la racionalidad instrumental neoclásica saltan a la vista desde el momento en que culturalmente los científicos sociales se empiezan a preocupar por el estudio de las prácticas autárquicas de las comunidades indígenas, campesinas, afro descendientes, gremiales y familiares. Las experiencias de la cotidianidad en los procesos de intercambio mercantil de estos conglomerados humanos se afianzan en esquemas de comercio que no están atravesados por la lógica del mercado occidental (competencia perfecta, monopolio, competencia monopolística y oligopolio) e incluso ni por la supremacía del dinero -mercancías sagradas, la fiesta, la reciprocidad, el sacrificio el don-, porque sus intenciones posiblemente están superando la tendencia agresiva de la acumulación del capital (Marx, 1867/1977; 1844/1993) prevaleciente en la sociedad mercantil moderna. Como las categorías de la «premodernidad» vs la «modernidad» están todavía ausentes en el imaginario de estas colectividades, lo más usual para comprender el desarrollo de sus vínculos económicos es empezar por reconocerlas dentro de los espacios de la autenticidad, sin que esto implique una ruptura de orden mitológico ni epistémico para su permanencia en el tiempo. Aceptar otras posibles economías -emotivas, morales, de la razón-, diferentes a la racionalidad instrumental de occidente, es un gran paso para comprender nuestra existencia multicultural, a pesar de las contradicciones en que el capitalismo salvaje nos ha mantenido durante mucho tiempo.

Palabras claves: Economía de Mercado, Economías Alternativas, Economías Emotivas, Economías Morales, El Don, El Mito, Diversidad, Identidad, Sociedad de Consumo, Racionalidad Instrumental.

\section{ABSTRACT}

The possibility of other economies other than the microeconomic structures imparted by neoclassical instrumental rationality are evident from the moment cultural social scientists are beginning to worry about the study of the autarchic practices of the indigenous, peasant, Afro-descendant communities, Guilds and family members. 
The everyday experiences in the mercantile exchange processes of these human conglomerates are consolidated in trade schemes that are not crossed by the logic of the western market (perfect competition, monopoly, monopolistic competition and oligopoly) and even by the supremacy of money - sacred marriages, festivity, reciprocity, sacrifice, the gift - because their intentions are possibly overcoming the aggressive tendency of the accumulation of capital (Marx, 1867/1977, 1844/1993) prevailing in modern mercantile society. Since the categories of "premodernity" versus "modernity" are still absent in the imaginary of these collectivities, the most usual thing to understand the development of their economic bonds is to begin by recognizing them within the spaces of authenticity, without implying A rupture of mythological or epistemic order for its permanence in the time. Accepting other possible economies -emotional, moral, reason-, different from the instrumental rationality of the West, is a great step to understand our multicultural existence, despite the contradictions in which savage capitalism has kept us for a long time.

Key words: Market Economy, Alternative Economies, Emotional Economies, Moral Economies, Gift, Myth, Diversity, Identity, Consumer Society, Instrumental Rationality.

"Los economistas tienen una manera singular de proceder. Para ellos no hay más que dos clases de instituciones: las del arte y las de la naturaleza. Las instituciones del feudalismo son instituciones artificiales, $y$ las de la burguesía son instituciones naturales. En lo cual se parecen a los teólogos, que establecen también dos clases de religiones: toda religión que no es la de ellos es una invención de los hombres, al paso que su propia religión es una emanación de Dios" (Karl Marx) ${ }^{1}$.

Con el advenimiento del sistema capitalista (Inglaterra siglo XVI) se impone a nivel global la lógica instrumental del mercado, bajo la apariencia y el velo de la libre movilidad entre la oferta y la demanda, dentro de un contexto regulado por la soberanía del consumidor, la maximización de beneficios por la vía de la minimización de costos, la utilización racional de los recursos escasos, la teoría del bienestar, la especulación financiera y todo aquello que se

1. Véase, Karl Marx (1847/1999). Miseria de la filosofía. Contestación a la «Filosofía de la Miseria» de Proudhon. Ediciones Folio, traducción de José Mesa, Villatuerta (Navarra), España, p. 137. aproxime monetariamente al principio de la eficiencia económica. Con estas caracterizaciones económicas, la supremacía de occidente se expande por la mayor parte del mundo, revirtiendo incluso las prácticas de otras economías cuyas dinámicas no se fundamentan en el mercado ni en el poder del dinero -el don (Mauss, 1971), la fiesta, la mercancía sagrada, las economías emotivas, las economías de la moral y la razón- (Bataille, 1998). El auge del capitalismo, a pesar de llevar implícita «una idea de progreso» y «desarrollo» creó serías inconsistencias estructurales para la mayor parte de las culturas $\mathrm{y}$ tradiciones locales, y en especial para aquellas que se resisten al torbellino de la modernidad ${ }^{2}$.

Las estructuras de mercado como la competencia perfecta, los monopolios, los oligopolios y los mercados monopolísticos han resuelto en parte la lógica

2. Véase, Karl Marx (1848/1971). Manifiesto del partido comunista. Ediciones en lenguas extranjeras, Pekín. Capítulo I: Burgueses y proletarios, pp. 32 -54 . 
del proceso de acumulación de capital a ultranza de la condición humana de la mayor parte de los pueblos existentes sobre la faz de la tierra, por cuanto han deteriorado las relaciones sociales más íntimas hasta llegar el extremo de convertir las pasiones y los sentimientos individuales en una simple racionalidad que está mediada por el poder del intercambio mercantil y monetario ${ }^{3}$ :

"La noción de que el comercio en las economías no monetizadas y preindustriales es generalmente visto como antisocial desde el punto de vista de las comunidades vecinas y por tanto, como algo restringido a menudo a tratos con los forasteros, tiene su contraparte en la perspectiva de que el espíritu del obsequio y el de la mercancía son profundamente opuestos. Según este planteamiento, el intercambio de obsequios y el mercantil son fundamentalmente contrarios y mutuamente excluyentes" (Appadurai, 1991: 26).

Hombres y mujeres de todas las clases, sexos y razas acuden voluntariamente día tras día, a un acto discrecional de intercambio de bienes y servicios que les permite adquirir lo necesario para subsistir en una «guerra de todos contra todos», es decir, dentro de un escenario en donde la «mano invisible» no siempre supera las expectativas del

3. El intercambio mercantil está mediado por el dios dinero, sin embargo, hay economías que no están reguladas por la acción intermediaria del dinero como signo de valor, pues su adquisición tiene un semblante mítico, religioso, afectivo, moral, emotivo y de tradición colectiva cuyas intenciones sagradas y culturales superan cualquier figura de representación monetaria o equivalente para el intercambio. De acuerdo con Marcel Mauss (1971), la figura del "Don" va más allá de la instrumentalización del dinero metálico o el papel moneda, porque el acto simbólico de dar es recíproco y se espera de la contraparte recibir algo como contraprestación, pero no necesariamente ese recibir debe ser equitativo en forma mensurable, pues es posible que la nueva donación sea superior en términos de prestigio y reputación de la comunidad a la cual se pertenece. bienestar económico, porque detrás de todos los actos visibles del mercado opera también la intención del ánimo de lucro egoísta y egocéntrico del empresario capitalista, quien actúa como regulador directo de los vínculos entre los individuos como sujetos pasivos del consumo y la relación capital-trabajo en la esfera de la producción, bien sea ésta de corte manufacturo o industrial. Cuando el tecnicismo de occidente se impone como el imperio de la verdad, auspiciada regularmente por la exegética del positivismo en las ciencias, las relaciones de producción, distribución cambio y consumo quedan totalmente mediatizadas por el dominio de una razón sujeta a los juicios de valor pregonados por la acumulación de capital, la explotación del hombre por el hombre, la depredación del medio ambiente $\mathrm{y}$ la descomposición social en economías cuyo dinamismo no ha sido capaz de superar la pasión del deseo fetichista de las mercancías (Marx, 1867/1977, 1844/1993):

"Los ritos de producción en las minas de estaño en Bolivia y su mitología asociada no constituyen un simple remanente de ritos campesinos de producción. Reflejan las tensiones de una sociedad donde la mercantilización no se ha vuelto un lugar común, donde el fetichismo de las mercancías, debido a esta hegemonía incompleta, se considera maligno y peligroso y, en consecuencia, tiene un lugar paradójico de envolver al demonio en ritos recíprocos. Este no es el fetichismo mercantil en el clásico sentido marxista (donde los productos esconden y representan relaciones sociales), sino un fetichismo más literal, en el cual la mercancía, iconizada como el demonio, se convierte en el pivote de un conjunto de transacciones rituales dirigidas a eclipsar los riesgos cosmológicos y físicos de la minería" (Appadurai, 1991: 74). 
Las estructuras de los mercados dominantes en la tradición económica de occidente y en especial las regidas por las prácticas comerciales del capitalismo, inducen permanentemente a estimular una conducta de consumo repetitiva en términos de la evolución de las mercancías y su capacidad de generar contradicciones entre la necesidad, el ser y el tener ${ }^{4}$. Los impactos de oferta y la moda van creando paulatinamente la velocidad en el consumo, bien sea éste de bienes básicos o de productos suntuarios con mercados exclusivos, lo importante es que por encima del orden natural prevalezca la intención de comprar y vender aunque el deseo no exista; ya que, la publicidad se ha encargado de forma agresiva de introducir la pasión comercial de poseer las mercancías mediante la velocidad en el uso y su carácter perecedero en el tiempo, pues aunque éstas sigan existiendo como objetos físicos, realmente la sociedad líquida ${ }^{5}$ las va desplazando rápidamente para crear otros nichos de mercado en la órbita de la circulación del capital y la nuevas necesidades creadas por una cultura de consumo masivo inducido por la industria moderna.

Las mercancías en los mercados regulados por la ley de la oferta y la demanda se proyectan ante el consumidor mediante el mecanismo de los precios, tal como si llevaran en la

4. Véase, Jean Baudrillard. Crítica de la economía política del signo. Siglo XXI Editores, quinta edición en español, México D.F., 1983. Capítulo II: “Génesis ideológica de las necesidades”, pp. 52-87; Capítulo VIII: "Hacia una economía política del signo", pp. 166-193.

5. Véase, Zygmunt Bauman. Vida líquida. Editorial Paidós, serie Estado y Sociedad, No. 143, traducción de Albino Santos Mosquera, Barcelona - España, 2006. Capítulo V: "Consumidores en la sociedad moderna líquida”, pp. 109-153. frente su propio nombre y demás resabios mitológicos que existen en su propia materialidad y corporeidad física (Marx, 1848/1977). La estructura de los precios en el paradigma económico occidental es una forma de la identidad del bien o servicio que circula por los diferentes mercados a la espera de un consumidor consciente o alienado que esté en las condiciones de solvencia financiera para asumir la acción social del intercambio/monetario, tanto de bienes simbólicos ${ }^{6}$ como de objetos rápidamente desechables para una sociedad cada vez menos satisfecha por las condiciones de reproducción de sus necesidades ficticias. Las economías que están reguladas por la libre movilidad entre compradores y vendedores en estructuras mercantiles sólidas, están directamente condicionadas por el poder del dinero, la publicidad, las modas, las ofertas, las realizaciones en subastas y la manipulación cotidiana del deseo a través de los medios masivos de información como la radio, la presa, la televisión, el teléfono y el internet:

"A causa de que las generaciones burguesas han podido gozar de la decoración fija y secular de la propiedad, es por lo que sus herederos pueden hoy darse el lujo de renegar de la piedra sillar y exaltar lo efímero: esta moda les pertenece. En cambio, todas las generaciones de clases inferiores, cuyas posibilidades en el pasado de tener acceso a los modelos culturales a la vez que a la propiedad duradera fueron nulas, ¿a qué se quiere que aspiren, sino a vivir ellas también el modelo burgués, y a fundar a su vez, para ellas y para sus hijos, una

6. Véase, Georges Bataille (1998). Teoría de la religión. Ed. Taurus, Madrid - España. Primera parte. Capítulo II: "La humanidad y la elaboración del mundo profano", pp. 31-45; capítulo III: "El sacrificio, la fiesta y los principios del mundo sagrado", pp. 47 - 65. Segunda parte. Capítulo IV: "El desarrollo industrial", pp. 91-113. 
dinastía irrisoria en el cemento de las residencias o el pedernal de las construcciones de los suburbios?, ¿cómo se puede exigir de esas clases hoy "promovibles" que no sacralicen los bienes inmuebles y acepten de golpe el idealismo de las estructuras móviles? Han nacido para desear lo que dura, y esta aspiración no hace más que reducir su destino cultural de clase" (Baudrillard, 2007: 35).

En las nuevas sociedades postindustriales (Bell, 1976), los consumidores se califican como ciudadanos dependiendo de sus patrones de consumo y de los lugares en donde viven o desarrollan su vida social; por consiguiente, para ciertos estratos de la población es fundamental para el desarrollo de sus vacías existencias, la complementación cotidiana de objetos materiales como el vehículo, el apartamento, la motocicleta (Marcuse, 1993) y demás bienes que definen los criterios de un buen nivel de vida en términos del disfrute de ciertas comodidades que no están al alcance de todas las personas; simplemente, porque los bienes se han clasificado también de acuerdo a las categorías de quienes los enajenan (Marx, 1848/1993), es decir, están hechos para consumidores de clase alta, media o baja en mutua correspondencia con los diferentes niveles de ingreso de la sociedad. En este orden de categorizaciones la microeconomía de la empresa capitalista nos ofrece en forma muy instrumental la descripción de bienes normales, inferiores y de lujo, los cuales están directamente relacionados con el comportamiento de la elasticidad ingreso de la demanda y las prácticas culturales del consumo.

Lo anterior implica asimilar las conductas del consumidor y sus respectivas sensibilidades ante la variación en el ingreso en sociedades en donde la regulación de los salarios sigue siendo totalmente desigual, lo cual quiere decir, que el mercado a pesar de asumir las responsabilidades en el intercambio de bienes y servicios, se comporta en forma excluyente o selectiva. La libertad económica de elegir los patrones de consumo es más un mito de la racionalidad instrumental que de la misma elección del consumidor, pues todas sus preferencias están condicionadas por la restricción en el ingreso y las conductas psicológicas del individuo a la hora de tomar decisiones sobre sus hábitos de compra.

Tanto productores como consumidores en las economías de mercado actúan bajo el principio de los incentivos derivados de cada transacción sin importar cuál sea la estructura de mercado prevaleciente en el momento de la toma de decisiones sobre el tipo de bienes a consumir. Si el intercambio se realiza en un escenario en donde predomina la «competencia perfecta», el individuo como sujeto activo interactúa mecanizado bajo las siguientes características del entorno económico: a) el producto es homogéneo, b) el precio lo determina la libre movilidad entre la oferta y la demanda, c) existe plena información del mercado, d) hay libre movilidad de recursos e) se puede entrar y salir fácilmente del mercado sin ningún tipo de restricción. Esto suena un poco paradójico en sociedades donde la avaricia y la ambición permanente de lucro incitan a la competencia desleal mediante la práctica de otras formas de intercambio que están por fuera de los designios de un mercado perfecto en relación con las conductas de los consumidores y productores: en la actualidad son muy po- 
cos los productos que se ajustan a estos criterios de la racionalidad microeconómica neoclásica.

Aunque nuestras «culturas precolombinas» no construyeron en sus imaginarios la instrumentalización económica de los modelos impartidos por occidente, el auge de las fuerzas productivas y las relaciones de producción del capitalismo las ha absorbido en su mayoría hasta depredarlas de sus prácticas más ancestrales tales como la singularización mítica hacia ciertos objetos cuyo valor está representado en lo sagrado y no en el dinero (Mauss, 1971; Appadurai, 1991). El carácter dominante de los monopolios desde el siglo XIX, hizo de la economía una ciencia al servicio del capital y de quienes se apropiaron de los medios de producción a través de la historia mediante actos salvajes de expropiación y titulación de los factores de la producción: capital, tierra y trabajo, es decir, la acumulación primitiva como prehistoria del capital es un proceso violento de proletarización de la mano de obra y de privatización de la madre tierra (Marx, 1867/1977):

"La metáfora fetichista consiste, en un sincretismo heredado de las representaciones primitivas, analizar los mitos, los ritos, las prácticas, en términos de fuerza, de fuerza mágica trascendente, de mana (cuyo último avatar sería eventualmente la libido), fuerza transferida a seres, a objetos, a instancias, fuerza difusa y universal pero cristalizada en puntos estratégicos y cuyo flujo puede ser regulado y desviado en beneficio suyo por el individuo o el grupo: tal será el objetivo mayor de todas sus prácticas, incluso alimentarias. Así se despliega la visión animista: todo ocurre entre las hipóstasis de una fuerza, su trascendencia peligrosa, y la captura de esa fuerza que deviene entonces benéfica. En estos términos es como los indígenas han racionalizado su experiencia del mun- do o del grupo. En los mismos términos es como los antropólogos han racionalizado su experiencia de los indígenas, conjurando con ello la interrogación crucial que hacían pesar estas sociedades nuevas sobre su propia civilización" (Baudrillard, 2007: 89).

El monopolio como práctica económica tiene una connotación individualista por parte de los productores al inducir el hábito de la compra - venta a unas condiciones mucho más desiguales desde el punto de vista de las relaciones sociales, ya que, la mercancía objeto de esta práctica comercial es ofrecida únicamente por un solo empresario, lo cual le da el privilegio de fijar los precios y los márgenes de ganancia de acuerdo a sus propias expectativas de acumulación. Como bien se puede apreciar, el legado de occidente en materia de economía es contraproducente e irracional para nuestras culturas nativas que muy poca relación tienen con estas prácticas de intercambio y de reproducción social, pues en su mayoría están determinadas por el mito, el intercambio recíproco -el don ( Mauss, 1971)-, el trueque, la mercancía sagrada (Geary, 1991), la fiesta y la emotividad; mientras en el paradigma dominante occidental prevalecen la avaricia por la acumulación de capital, el deseo del tener inspirado en la propiedad privada y el atesoramiento del dinero proveniente del conjunto de las plusvalías derivadas del trabajo abstracto humano (Marx, 1844/1993).

El monopolio por ser exclusivo desde el punto de vista de la oferta se distingue por la imposición de barreras de entrada que limitan el campo de acción comercial de cualquier otro empresario interesado en incursionar en el mismo 
negocio con fines específicos de lucro. En estas condiciones, prácticamente la competencia no existe porque se encuentra fuertemente protegida por el capitalista industrial y el derecho positivo en cooperación con el poder del Estado, excepto aquellos monopolios de orden natural que a casi nadie le interesan por su baja competitividad. Las desigualdades económicas de una estructura como la del monopolio puro se reflejan en la pobre capacidad de compra de los sectores más vulnerables de cualquier sociedad regulada comercialmente por los destinos de un solo fabricante, quien a su libre albedrío puede controlar el sistema de precios, el mercado de los insumos (monopsonio), los volúmenes de producción y la tasa media de ganancia $\left(\mathrm{g}^{\prime}=\mathrm{p} / \mathrm{c}+\mathrm{v}\right)^{7}$ de cualquier sector de la industria; semejante escenario tan disímil para cualquier cultura aborigen o tradicional ${ }^{8}$ no existe porque rompe con la esencia de la vida cotidiana y las posibilidades del

7. $\mathrm{g}^{\prime}=\mathrm{p} / \mathrm{c}+\mathrm{v}$, es en la teoría marxista la cuota o tasa de ganancia y se define como la plusvalía sobre el capital fijo más el capital variable de cualquier organización o empresa productiva y desde el punto de vista de la composición orgánica del capital $(\mathrm{k}=$ $c+v$ ), a medida que el capital fijo (c) se incrementa, permaneciendo constante el capital variable (v), la tasa de ganancia disminuye paulatinamente con los incrementos en el capital fijo; lo anterior explica el surgimiento de las crisis del sistema capitalista por la vía de la tendencia decreciente de la cuota de ganancia, y aunque en las sociedades de la actual «globalización neoliberal» la crisis es financiera, sistémica y civilizacional, el deterioro de la tasa de ganancia sigue siendo un punto de referencia para explicar las dinámicas del sistema capitalista contemporáneo.

8. El intercambio sin dinero y las otras economías que no pertenecen a la tradición racional instrumental de occidente, no necesariamente son ancestrales ni aborígenes, éstas existen en las sociedades actuales como culturas con identidad propia e incluso se presentan ante el mundo capitalista occidental como focos de resistencia al no reproducir la dinámica instrumental de la economía y la cultura del mercado dominante de la actual sociedad postindustrial del siglo XXI. buen vivir, entendiendo este último no como una racionalidad del mercado, sino más bien, como un punto de encuentro equilibrado entre la producción, la vida y la madre naturaleza.

Las rígidas estructuras de los mercados monopolistas y oligopólicos son las predominantes en las sociedades modernas actuales cuyos destinos se rigen por las fuerzas del mercado, la competencia y el lucro incesante de inversiones cada vez más especializadas en tecnologías de punta. Mientras los oligopolios presentan más de dos oferentes de un producto en el mercado con todas sus gabelas de precios y competitividad, los mercados monopolísticos tienen una gran gama de productos muy parecidos en sus usos (productos heterogéneos), fácilmente diferenciables por su presentación, empaques y sustitutos cercanos (cigarrillos, jabones, televisores, celulares, microcomputadores, autos, servicios de hotelería etc.). Estas estructuras instrumentales/ dominantes/depredadoras de intercambio no prevalecen en las culturas locales/aborígenes/indígenas en donde la singularización de ciertos objetos de orden mitológico/religioso (Batalille, 1998) supera cualquier pretensión de estos modelos racionalmente elaborados para medir en parte la desigualdad entre los seres humanos. Desde los espacios de la autenticidad las culturas locales están elaborando sus propias economías de acuerdo con sus necesidades e «ideas de progreso y el buen vivir» dentro de lo realmente posible en términos de producción, distribución, cambio y consumo de bienes básicos para la subsistencia y la conservación de sus autonomías. Si bien estas prácticas de regulación económica sostenible 
operan dentro de una economía nacional y global, sus contextos responden a una tradición que se ha mantenido en el espacio y el tiempo (Kopytoff, 1991). Las otras economías -emotivas, morales, de la razón, trueque, cooperativismo, granja comunitaria, etc.-, por su condición autóctona no rechazan en su totalidad las fuerzas inherentes del mercado, pero ejercen simbólicamente una forma de resistencia a proyectos como el «neoliberalismo» y la «globalización» y reivindican desde sus condiciones locales el control sobre el medio ambiente, la madre naturaleza, el derecho a la autonomía de los pueblos y el respecto por sus ancestros culturales:

"Aquí cabe señalar varias cosas. En primer lugar, el consumo, y la producción de necesidades y deseos, es esencial. Todo está mercantilizado, y este proceso se refuerza con los constantes anuncios en televisión. Se presuponen los ingresos necesarios para mantener modos de vida consumistas, lo mismo que el ocio suficiente para permitírselos. Pero Princes Street también marca una vieja división social: los consumidores ostentosos al sur y los menos acomodados al norte. En segundo lugar, la ciudad también es escenario de cambios culturales. El cambio de estilo, de lo económico y lo funcional a lo cultural y estético también es claramente visible en las áreas urbanas; todo avance hacia la postmodernidad es metropolitano. En tercer lugar, la cultura del consumo puede relacionarse con otros fenómenos culturales más generales. No sólo los productos artísticos y de consumo, sino también los intelectuales e incluso los religiosos, están sometidos al mercado, que no reconoce ni monopolios ni jerarquías. Poca audiencia pueden tener aquí los pronunciamientos «autoritativos» de origen académico, religioso o político, aunque las respuestas defensivas pueden contribuir a crear un clima que conduzca al resurgir religioso o al mantenimiento de una utopía de índole marxista" (Lyon, 2000: 111).
Cuando una comunidad se resiste (Guha, 2002) 9 a consumir Coca-Cola, los enlatados de la industria nacional e internacional, los videos y películas de la industria cultural, la ropa importada y toda la «producción material e inmaterial» que circula por los medios de información, no está haciendo otra cosa que buscar alternativas para crear espacios de reconciliación con sus ancestros culturales. Singularizar los procesos de intercambio -recíprocos- mediante otras experiencias diferentes a las estructuras de mercado antes mencionadas y si es posible sin la participación del dinero, es una forma autárquica/ mítica/sagrada y sociocultural de resolver a nivel comunitario los estragos que implícitamente nos ha dejado el sistema capitalista durante siglos de explotación, tanto de los recursos naturales como de la fuerza de trabajo del hombre.

9. Históricamente el mundo ha evolucionado a través de guerras y conflictos para consolidar estructuras de poder cada vez más fuertes en términos de los principios de la autoridad y la obediencia, aunque, no siempre ha existido un linealidad político temporal en la conservación del orden, ya que, de diversas formas los marginados -obreros, campesinos, indígenas, afros, esclavos, intelectuales y pobres- se han rebelado ante el yugo de las colonialidades del poder y del saber a través de sus propias historias de colonización, explotación y dominación. Subvertir el orden ha tenido un precio oneroso en la historiografía de los movimientos sociales, más cuando, sus triunfos han sido efímeros, sin embargo: "Cuando un campesino se subleva en la época del Raj, lo hacía necesaria y explícitamente violando una serie de códigos que definían su misma existencia como miembro de aquella sociedad colonial y, en gran medida, todavía semifeudal. Su subalternidad se materializaba por la estructura de la propiedad, se institucionalizaba por la ley, se santificaba mediante la religión y se hacía tolerable -e incluso deseablepor la tradición. Sublevarse, por tanto, significaba destruir muchos de los símbolos familiares que había aprendido a leer y a manipular; para poder extraer un significado del duro mundo que le rodeaba y vivir en él. El riesgo de «perturbar el orden» en estas condiciones era tan grande que no podía permitirse embarcarse inconscientemente en un proyecto semejante" (Guha, 43: 2002). 
El rechazo directo de algunas comunidades locales al consumo de las mercancías provenientes del desarrollo de la gran industria induce a estas organizaciones a crear modelos alternativos de «desarrollo» auto sostenible para revertir la gran escalada del mecanismo de los precios, las modas, y los impactos de oferta en pleno auge de las comunicaciones y de la mercadotecnia. Experiencias como la del cooperativismo están inspiradas en los fundamentos teóricos del socialismo utópico francés e inglés (Charles Fourier, Robert Owen, Sismondi, Saint Simon entre otros), y aunque no resuelve en su totalidad las contradicciones del mercado, contribuye a eliminar los mecanismos de intermediación entre el productor y el consumidor para permitirle disfrutar de un mayor nivel de bienestar por la vía del poder adquisitivo del salario y la distribución más equitativa de los bienes y servicios; esto es lo que en última instancia los teóricos de las economías sostenibles han denominado como «capitalismo solidario». Las relaciones de intercambio de este modelo empresarial se definen por el factor " $\mathrm{C}$, solidaridad" o niveles de integración; sin embargo, siguen interactuando en economías de mercado con ciertos privilegios, pero en correspondencia con patrones de cambio definidos por las leyes de la oferta y la demanda:

"En la posición de una cosa, de un objeto, de un utensilio, o en la de un plano de los objetos (en el que los diversos semejantes del sujeto y el sujeto mismo adquieren un valor objetivo), en el mundo en el que los hombres se desplazan es todavía, de una manera fundamental, la continuidad a partir del sujeto. Pero el mundo irreal de los espíritus soberanos o de los dioses pone la realidad de un mundo profano, de un mundo de cosas y de cuerpos, se plantea frente a un mundo santo y mítico" (Bataille, 1998: 41).

Las granjas cooperativas resuelven también en parte algunos de los problemas agroalimentarios de los sectores más vulnerables del área rural mediante la formulación y puesta en marcha de proyectos agropecuarios de carácter sostenible en el corto y mediano plazo. Esto les ha permitido a algunos sectores campesinos superar las épocas de escasez de alimentos y eliminar en la etapa de la distribución a los intermediarios y especuladores que aprovechan los problemas de oferta alimentaria para disparar los precios de la canasta familiar. En la autonomía local el nacimiento de otras prácticas económicas va en contra vía de los procedimientos utilitaristas del empresario capitalista que por lo general siempre aspira a alcanzar con su actitud egoísta el máximo de beneficio $\left(\mathrm{p}^{*}=\mathrm{p} / \mathrm{v}=\mathrm{Te} / \mathrm{Tn}\right)^{10}$ con respecto a sus capitales invertidos ( $\mathrm{C}=$ capital fijo $+\mathrm{V}=$ capital variable), no importa si para lograrlo debe asumir comportamientos despreciables sobre el verdadero sentido de la condición humana, en especial cuando grandes sectores de la población se encuentran desguarnecidas y deben ceder ante el influjo de la inanición y la miseria para venderse al primer postor en el mercado de trabajo; así funcionan los principios de la libertad económica liberal:

"En el pensamiento occidental contemporáneo, damos más o menos por sentado

10. $\mathrm{p}^{*}=\mathrm{p} / \mathrm{v}$, se denomina cuota o tasa de plusvalía en la teoría marxista la cual también es equivalente a $\mathrm{Te} / \mathrm{Tn}$ o trabajo excedente sobre trabajo necesario, véase Karl Marx (1867/1977). Esta representación aritmética permite medir la explotación de los obreros en términos porcentuales, tomando como punto de referencia la incorporación al proceso productivo del capital variable o fuerza de trabajo. 
que las cosas -los objetos físicos y los derechos sobre ellos- representan el universo natural de las mercancías. En el extremo opuesto, colocamos a las personas, quienes representan el universo natural de individualización y singularización. Esta polaridad conceptual de personas individualizadas y cosas mercantilizadas es reciente $y$, culturalmente hablando, excepcional. Las personas pueden ser y han sido mercantilizadas una y otra vez en incontables sociedades a lo largo de la historia, mediante aquellas instituciones ampliamente difundidas y conocidas con el término general de esclavitud" (Kopytoff, 1991: 90).

La alternatividad económica está precisamente buscando la forma de revertir los procesos de exclusión social que ha provocado el sistema capitalista durante siglos con la explotación de la fuerza de trabajo y su discriminación prolongada en el tiempo por el antagonismo de la lucha de clases (Marx, 1848/1993). Las comunidades indígenas, afro descendientes, campesinas, barriales y obreras, están buscando otras posibilidades de producción e intercambio que les permita vivir mejor; es decir, por lo menos satisfacer dignamente las necesidades fundamentales (alimentación, vestido y techo) sin caer en los esquemas del asistencialismo del Estado, y procurando al máximo ser productivos dentro de una sociedad cada vez más excluyente desde el punto de vista de las reglas de juego impuestas por el mercado ${ }^{11}$.

11. El ser humano, alienado por la producción material e inmaterial es cosificado hasta el grado en que no logra diferenciarse de las máquinas, a pesar de ser éstas producto de su destreza y trabajo abstracto humano y en la mayoría de su interacción con la actividad productiva en la fábrica o en la industria actúa como un servomecanismo o apéndice del capital muerto; es decir, la producción lo domina y lo convierte en un ser totalmente enajenado (Marx, 1844/1993) e incapaz de liberarse por sus propios
El intercambio sin dinero fue muy usual en aquel período de la humanidad en donde las únicas fuentes de subsistencia eran la caza, la pesca y la recolección; sin embargo, todavía muchas culturas lo siguen practicando como una forma simbólica de mantener sus imaginarios colectivos, porque se resisten a ser demolidos por la «idea de progreso/capitalista» de la gran industria moderna. Hoy en los albores del siglo XXI, el trueque se sigue practicando como una posibilidad de intercambio/recíproco en comunidades indígenas de varios países, con el propósito de mantener un cierto nivel de arraigo por sus ancestros culturales; no obstante, la transacción final entre objetos de la naturaleza y los productos del trabajo humano está orientada a satisfacer las necesidades más apremiantes de quienes intervienen en el acto económico de cambio sin dinero. Para algunos científicos sociales (Antropólogos, Sociólogos e Historiadores) el hecho de replantear el intercambio sin la me-

medios del extrañamiento frente a los productos de su trabajo y ante sí mismo como un ser totalmente desnaturalizado; la producción industrial capitalista ha destruido la condición humana y la ha suplantado por el mundo de las cosas y el dios dinero de la actual sociedad de consumo. A las otras economías les queda el imperativo de dominar la producción para no fenecer en la construcción de otros mundos mejores y diferentes -al capitalismo salvaje-, en donde la enajenación no sea el referente fundamental del proceso de producción, distribución, cambio y consumo de los bienes necesarios para el disfrute de la vida: "Por una aparte disponemos, de salida, de la conciencia clara en su forma elaborada. El mundo de la producción, el orden de las cosas, ha alcanzado, por otra parte, el punto de desarrollo, en el que no sabe qué hacer con sus productos. La primera condición hace la producción posible; la segunda necesaria. Pero esto no puede ser hecho en el empíreo; por decirlo de otro modo, en la irrealidad en la que produce habitualmente la gestión religiosa. El momento de la decisión, por el contario exige la consideración de los aspectos más pobres y los menos íntimos. Es preciso ahora bajar hasta lo más bajo del mundo de la reducción del hombre a la cosa" (Bataille, 1998: 104). 
diación del papel moneda se constituye en una expresión de resistencia a la globalización de la economía; mientras que para los economistas tecnócratas/ neoclásicos/institucionalistas es una retaliación «premoderna» sobre la visión del nuevo mundo, construido por el avance desmesurado de las fuerzas productivas.

¿Cómo ubicar epistemológicamente el surgimiento de estas otras economías alternas? Los referentes se encuentran en la Antropología y los Estudios Culturales y aunque, los científicos sociales en las sociedades contemporáneas están avanzando en la elaboración de teorías, prácticas comunitarias e incluso en estrategias de resistencia al capitalismo global, no existe todavía suficiente claridad sobre cómo se insertarán estas economías en las nuevas estructuras de poder en un mundo tan racionalizado desde la lógica del capital y la soberanía del mercado; más cuando, para los economistas liberales/neoliberales y neoclásicos el dinero ha sido una de sus mejores invenciones. El poder del dinero (Marx, 1844/1993) se refleja en su capacidad que tiene como medio de compra y de pago, o como equivalente general del mundo de los negocios, por lo tanto, ha sido la mejor ilusión de la ciencia económica. El dinero como herramienta universal de intercambio superó las inconsistencias comerciales del mundo antiguo al corregir los inconvenientes presentados por el trueque desde la perspectiva de preferencias y unidades de medida para el canje entre comunidades; sin embargo, el dinero también ha transformado la conducta humana al alienarla mediante su poder de compra y seducción, tal como lo plantea Marx en la siguiente reflexión:
"Lo que soy y lo que puedo no están determinados en modo alguno por mí individualidad. Soy feo pero puedo comprarme la mujer más bella. Luego no soy feo, pues el efecto de la fealdad, su fuerza ahuyentadora, es aniquilado por el dinero. Según mi individualidad soy tullido, pero el dinero me procura veinticuatro pies, luego no soy tullido; soy un hombre malo, sin honor, sin conciencia y sin ingenio, pero se honra al dinero, luego también a su poseedor. El dinero es el bien supremo, luego es bueno su poseedor; el dinero me evita además, la molestia de ser deshonesto, luego se presume que soy honesto; soy estúpido, pero el dinero es el verdadero espíritu de todas las cosas icómo podría carecer de ingenio su poseedor? Él puede por lo demás, comprarse gentes ingeniosas, ¿y no es quien tiene poder sobre las personas inteligentes más talentoso que el talentoso? ¿Es que no poseo yo, que mediante el dinero puedo todo lo que el corazón humano ansía, todos los poderes humanos? ¿Acaso no transforma mi dinero todas mis carencias en su contrario?" (Marx, 1844/1993: 183-183).

Pero detrás de las bondades del dinero existe toda una enajenación de los hombres sobre esta clase de fetiche que transustancia los deseos humanos bajo la premisa del tener; el dinero: "Es la puta universal, el universal alcahuete de los hombres y de los pueblos" (Marx, 1844/1993). Con el dinero se puede comprar de todo, hasta el pasaporte a la vida celestial y convertir lo malo en bueno, lo feo en hermoso, las debilidades en fortalezas y lo humano demasiado humano en conductas despreciables (Marx, 1844/993). La crítica sobre el uso del dinero como medio de cambio debe estar orientada hacia el poder destructor de las relaciones entre los hombres y no a sus capacidades como instrumento de intercambio: 
"En general el valor es una propiedad que se atribuye al objeto; el modo en que se lleva a cabo dicha atribución se origina en determinado contexto social y es, en cierto grado - a menudo significativo-, arbitrario. El valor no es nunca una propiedad inherente al objeto o al material, en el sentido en que sí lo son los atributos físicos y mensurables tales como la dureza, la densidad, el índice de refracción, etcétera. El valor no puede medirse fuera del contexto social. Cuando nos referimos al valor en tanto cualidad inherente al objeto o la mercancía, estamos creando una metáfora o enmascarando una realidad" (Renfrew, 1991: 199).

Queda por demostrar en la praxis social hasta cuando estas experiencias que se han calificado como otras economías tienen permanencia en el espacio y el tiempo y no se dejan devorar por la innovación auto destructora de una modernidad cada vez más líquida. ${ }^{12}$ La dialéctica evanescente de los tiempos modernos nos permitirá tarde que temprano reconocer si estos esfuerzos valieron la pena, o si simplemente se quedaron como experiencias aisladas en contraposición al desarrollo de las fuerzas productivas y la «idea de progreso/capitalista». Aunque no queramos reconocerlo, las economías de mercado, el poder del dinero, la industrialización, la producción en masa, la aplicación de la tecnología de punta en los procesos productivos y la revolución en las comunicaciones, nos han llevado en forma masiva a consolidar una sociedad de consumo que por sus propias contradicciones le ha dejado a

12. Véase, Zygmunt Bauman. Modernidad líquida. Editorial Fondo de Cultura Económica, traducción de Mirta Rosenberg en colaboración con Jaime Arrambide Squirru, quinta reimpresión, Buenos Aires - Argentina. Capítulo 2: "Individualidad", pp. 59-98; Capítulo 3: "Espacio/Tiempo", pp. 99-138. la sociedad como un conjunto de individuos el imperativo de la soberanía al consumidor. La dualidad entre lo sólido y lo líquido en la fragilidad de los sentimientos humanos es una prueba más para saber que aunque nada es eterno y todo tiende a desaparecer de acuerdo a la segunda ley de la termodinámica; nos reconforta la esperanza por encontrar otros mundos posibles en medio de la actual crisis global. Que todo tienda a cambiar en sociedades cada vez más fragmentadas por el poder del mercado, el dinero, la industria y la sociedad de consumo (Lipovetsky, 2007), es también una muestra fehaciente de saber que todavía estamos vivos (Berman, 1991), no sólo para contárselo a nuestras futuras generaciones, sino también para transformar el contexto social de quienes afrontan las calamidades del sistema capitalista en el mundo de hoy.

\section{Conclusiones}

Las economías de mercado occidentales han depredado los procesos de intercambio de las culturas indígenas y las han sometido a la supremacía del dinero como instrumento de cambio y signo de valor, sin embargo, estas culturas se resisten a ser aniquiladas y aún siguen practicando formas autóctonas de economías no capitalistas como el trueque, el don y las reciprocidades emotivas de la moral y la razón. La economía neoclásica con sus estructuras de mercado rígidas -competencia perfecta, monopolio, oligopolios, monosopnios y oligosopnios- y su racionalidad instrumental desconocen cualquier otra práctica económica que no esté orientada a la generación de beneficios monetarios e imponen desde el eurocentrismo las colonialidades del poder y del saber 
que por mucho tiempo han invisibilizado las culturas nativas, aborígenes, tradicionales y actuales de otros pueblos cuyas expresiones de intercambio son totalmente distintas al lucro y la depredación de la madre tierra.

El don, la fiesta, el trueque, el mito religioso y las emotividades como categorías de intercambio propias de culturas no alienadas por la industria comercial moderna representan un proyecto de vida y de equidad distributiva entre el ser humano y la naturaleza, porque están reguladas por afectos, sentimientos, emotividades, el sacrificio, ritos, mitos y en algunos casos por la religiosidad; por consiguiente, no tienen en sus imaginarios la destrucción del medio ambiente en beneficio del desarrollismo, sino por el contrario, estas prácticas económicas responden a identidades colectivas que no están atravesadas por el poder del dinero.

A diferencia de las prácticas económicas de la economía convencional -el paradigma eurocéntrico- el don como medio de intercambio es recíproco y espera de la contraparte su aporte en términos de sacrificio y prestigio social; por lo tanto, el don como figura del imaginario colectivo va más allá del simple intercambio de productos y utensilios necesario para sostenimiento de la vida, porque además del acto de dar y recibir está también presente la imagen y el prestigio social de quienes asumen la voluntad de entregar más de lo usualmente necesario; entonces, en este trance no tienen ninguna validez las teorías del valor, los precios y la ganancia tan fuertemente difundidas en la tradición de la economía política/ positivista contemporánea.
El dinero como instrumento de cambio ha sido una de las mejores invenciones de la ciencia económica positivista occidental porque permitió realizar intercambios que eliminaron la compra/ venta equivalente entre mercancías -el trueque- y fortaleció el comercio a nivel mundial, pero, cuando se trata de valorar la conducta humana, el dinero ha degenerado y prostituido (Marx) sus alcances económicos para fetichizar cualquier acción de consumo mediante la apología a una filosofía del tener en detrimento de la verdadera edificación del ser: el hombre mercancía. 


\section{BIBLIOGRAFÍA}

Anderson, Denedict (2007). Comunidades imaginadas. Reflexiones sobre el origen de la difusión del nacionalismo. Traducción de Eduardo L. Suárez, cuarta reimpresión. México D.F.: Editorial Fondo de Cultura Económica.

Baudrillard, Jean (1983). Crítica de la economía política del signo. 5º edición, México D.F.: Siglo XXI Editores.

(2004). El sistema de los objetos. Traducción de Francisco González Aramburu, decimoctava edición. México D.F.: Siglo XXI Editores.

Bauman, Zygmunt (2006a). Vida líquida. Serie Estado y Sociedad, No. 143, traducción de Albino Santos Mosquera. Barcelona, España: Paidós.

(2006b). Modernidad líquida. Traducción de Mirta Rosemberg en colaboración con Jaime Arrambide Squirru, quinta reimpresión. Buenos Aires, Argentina: Fondo de Cultura Económica

Bataille, Georges (1998). Teoría de la religión. Texto establecido por Thadée Klossowski. Madrid, España: Editorial Taurus.

Bell, Daniel (1976). El advenimiento de la sociedad postindustrial, un intento de prognosis social. Madrid, España: Alianza Editorial S.A.

Berman, Marshall (1991). Todo lo sólido se desvanece en el aire. La experiencia de la modernidad. Quinta edición en español. México, D.F.: Siglo XXI Editores.

Divignaud, Jean (1993). "El desafío", en: El sacrificio inútil. Traducción de Jorge Ferreiro Santana, capítulo III. México D.F.: Fondo de Cultura Económica.

Foucault, Michel (2008). Nacimiento de la biopolítica. Traducción de Horacio Pons, primera reimpresión. Avellaneda, Buenos Aires, Argentina: Fondo de Cultura Económica.

Geary, Patrick (1986) "Mercancías sagradas: la mercantilización de las reliquias medievales", en la compilación: La vida social de las cosas. Perspectiva cultural de las mercancías. Arjun Appadurai Editor, traducción de Argelia Castillo Cano, primera edición en colección de los noventa. México D.F.: Editorial Grijalbo.

Guha, Ranahit (2002). Las voces de la historia y otros estudios subalternos. Traducción de Gloria Cano, Barcelona, España: Editorial Crítica.

Grosso, José Luis (2012). Del socioanálisis a la semiopraxis de la gestión social: Contranarrativas en la telaraña global. Popayán, Colombia: Universidad del Cauca.

Hermo, Darío \& Miotti, Laura -Coordinadores- (2010). Biografías de paisajes y seres. Ilusiones desde la arqueología sudafricana. Primera edición, Buenos Aires, Argentina: Encuentro Grupo Editor/Editorial Brujas.

Klossowski, Pierre (2010). La moneda viviente. Traducción de Axel Gasquet, primera edición. Buenos Aires, Argentina: Las Cuarenta.

Kopytoff, Igor (1986). "La biografía cultural de las cosas: La mercantilización como proceso", en la compilación: La vida social de las cosas. Perspectiva cultural de las mercancías. Arjun Appadurai Editor, traducción de Argelia Castillo Cano, primera edición en colección de los noventa. México D.F.: Editorial Grijalbo.

Lipovetsky, Gilles (2007). La felicidad paradójica. Ensayo sobre la sociedad de hiperconsumo. Colección Argumentos, traducción de Antonio Prometeo Mora. Barcelona, España: Editorial Anagrama.

Lee, Matt \& Fisher, Mark (2009). Deleuze y la brujería. Traducción de Juan Salzano, primera edición. Buenos Aires, Argentina: Las Cuarenta. 
Marcuse, Herbert (1993). El hombre unidimensional. Ensayo sobre la ideología de la sociedad industrial avanzada. Traducción de Antonio Elorza. Barcelona, España: Editorial Planeta Agostini.

Marx, Karl (1848/1971). Manifiesto del partido comunista. Ediciones en lenguas extranjeras, 3 impresión, Pekín, República Popular China.

(1867/1977). El capital. Décima tercera reimpresión, traducción de Wenceslao Roces, Tomo I, Bogotá, Colombia: Fondo de Cultura Económica.

(1844/1993). Manuscritos: economía y filosofía. Traducción, introducción y notas de Francisco Rubio Llorente. Barcelona, España: Editorial Altaya.

(1847/1999). Miseria de la filosofía. Contestación a la filosofía de la miseria de Proudhon. Traducción de José Mesa, Villatuerta, Navarra, España: Ediciones Folio.

Mauss, Marcel (1971). Ensayo sobre los dones: razón y forma del cambio en las sociedades primitivas/1923, texto en PDF. Madrid, España: Editorial Tecnos.

Sen, Amalaya K (2002). La desigualdad económica. Traducción de Eduardo L. Suárez Galindo, primera reimpresión, México D.F.: Fondo de Cultura Económica.

(2004). "Los tontos racionales: una crítica de los fundamentos conductistas de la teoría económica" en: Filosofía y teoría económica. Compilado por Frank Hahn y Martín Hollis, traducción de Eduardo L. Suárez, primera reimpresión. México D.F.: Fondo de Cultura Económica.

Thompson, E.P. (1995). Costumbres en común. Traducción de Jordi Beltrán \& Eva Rodríguez, Barcelona, España: Editorial Grijalbo. 